
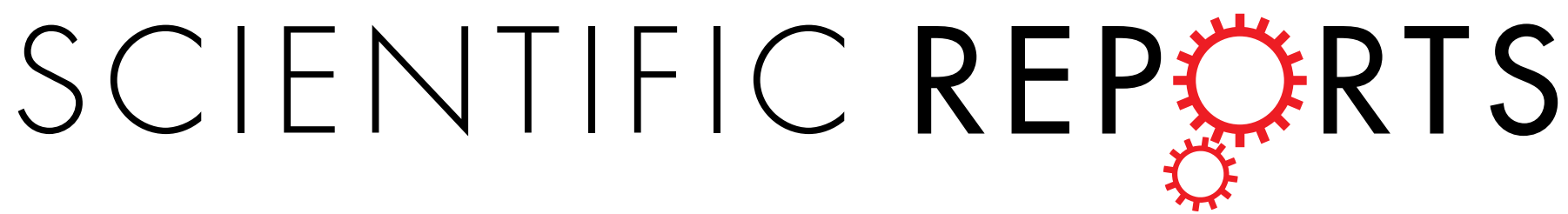

\title{
OPEN Kinetic Modeling of Phosphate Adsorption by Preformed and In situ formed Hydrous Ferric \\ Oxides at Circumneutral pH
}

Received: 13 May 2016

Accepted: 27 September 2016

Published: 14 October 2016
Yanpeng $\mathrm{Mao}^{1}$ \& Qinyan Yue ${ }^{2}$

Kinetics of phosphate removal by Fe(III) was investigated by both preformed and in situ formed hydrous ferric oxides (HFO) at $\mathrm{pH}$ 6.0-8.0. A pseudo-second-order empirical model was found to adequately describe phosphate removal in the two cases. The Elovich and intra-particle diffusion models, however, were only capable of describing phosphate adsorption to preformed HFO (PF-HFO). By using surface complexation kinetic models (SCKMs) to describe phosphate adsorption to PF-HFO, the adsorption rate constant $\left(0.0386-0.205 \mathrm{mM}^{-1} \mathrm{~min}^{-1}\right.$ for SCKM-1 and 0.0680-0.274 $\mathrm{mM}^{-1} \mathrm{~min}^{-1}$ for SCKM-2) decreased with increasing $\mathrm{pH}$ while the protonation reaction rate constant in SCKM-2 (0.0776-0.0947 $\left.\mathrm{mM}^{-1} \mathrm{~min}^{-1}\right)$ increased over the $\mathrm{pH}$ range 6.0-8.0. Using the rate constants obtained from the process of phosphate adsorption to PF-HFO, the amount of active surface sites on the in situ formed HFO were calculated as $0.955 \pm 0.170,1.46 \pm 0.39$ and $2.98 \pm 0.78 \mathrm{mM}$ for $\mathrm{pH}=6.0,7.0$ and 8 , respectively. Generally, as the SCKMs incorporate phosphate complexation on HFO surface sites and protons competiting for the surface sites, they could provide a good description of the rate and extent of phosphate removal by both preformed and in-situ formed HFO over a wide range of conditions.

To achieve high-efficiency phosphate removal from wastewaters, chemical precipitation of phosphorus using salts of aluminum (such as aluminum sulfate), iron (such as ferric chloride) or calcium (such as lime) is normally used ${ }^{1-4}$. Ideally, to removal phosphate by $\mathrm{Fe}(\mathrm{III})$, the most effective route is to form $\mathrm{FePO}_{4}(\mathrm{~s})$, in which the formation of a solid possesses a 1:1 molar ratio of $\mathrm{Fe}$ and $\mathrm{P}$. However, the rate constants for formation of $\mathrm{FePO}_{4}(\mathrm{~s})$ at $\mathrm{pH}$ 6.0-8.0 are at least two orders of magnitude lower than the rate constants for $\mathrm{Fe}$ (III) hydrolysis and precipitation over this $\mathrm{pH}$ range (Mao et al., unpublished). As such, the phosphate removal mechanism on addition of Fe(III) salts is unlikely to involve the precipitation of $\mathrm{FePO}_{4}(\mathrm{~s})$ but, rather, the formation of hydrous ferric oxides (HFO) followed by phosphate adsorption. Additionally, Galarneau and $\mathrm{Gehr}^{5}$ confirmed that phosphate removal using $\mathrm{Al}(\mathrm{III})$ salts involves production of $\mathrm{Al}(\mathrm{OH})_{3}(\mathrm{~s})$, followed by phosphate adsorption to this oxyhydroxide. Smith et al. ${ }^{6}$ have made the case that phosphate removal by $\mathrm{Fe}(\mathrm{III})$ salts is likely to be dominated by phosphate adsorption to $\mathrm{HFO}$ rather than precipitation of the more soluble $\mathrm{FePO}_{4}(\mathrm{~s})$.

While the rate of formation of HFO at circumneutral $\mathrm{pH}$ is recognized to be rapid, the rate (and extent) of phosphate adsorption by HFO has been shown to be strongly dependent on a variety of factors including the age or crystallinity of the iron oxide and the presence of competing anions and sorbing substrates such as natural organic matter ${ }^{7}$. Extensive research has been published on the kinetics of phosphate adsorption by stable crystalline iron oxides or modified iron oxides including goethite ${ }^{8-9}$, iron hydroxide-eggshell waste ${ }^{10}$, activated carbon loaded with $\mathrm{Fe}$ (III) oxide ${ }^{11}$, ferric sludge ${ }^{12}$ and iron oxide tailings ${ }^{13}$. However, there has been surprisingly little work on the kinetics of phosphate adsorption by freshly formed hydrous ferric oxide. Shang et al. ${ }^{14}$ examined and modeled phosphate adsorption by short-range ordered aluminum and iron precipitates, while Crosby et al. ${ }^{15}$ investigated phosphate adsorption by iron oxyhydroxides. However, neither the adsorption mechanism nor the effect of $\mathrm{pH}$ on the kinetics of phosphate adsorption to HFO were clearly elucidated in these studies.

\footnotetext{
${ }^{1}$ National engineering laboratory for coal-fired pollutants emission reduction, School of Energy and Power Engineering, Shandong University, Jinan 250100, PR China. ${ }^{2}$ School of Environmental Science and Engineering, Shandong University, Jinan 250100, PR China. Correspondence and requests for materials should be addressed to Y.M. (email: maoyanpeng@sdu.edu.cn)
} 
There have been many publications dealing with phosphate adsorption kinetics, typically describing phosphate removal by either first- or second-order expressions derived from Langmuir kinetics ${ }^{16}$, the Elovich model ${ }^{17-19}$, or the intra-particle diffusion model ${ }^{20,21}$. While founded in mechanistic principles, the expressions are typically empirical in nature, with little attempt made to relate to particular processes or chemical reactions. Only a few researchers have attempted a more process oriented approach. Shen and Duvnjak ${ }^{22}$ developed a reversible surface reaction model to describe cupric ion adsorption onto corncob particles, in which the kinetic constants for the forward reaction (adsorption) and backward reaction (desorption) were determined. As the protonation of surface sites was neglected in this model, the rate constant for the forward reaction may be overestimated, or, alternatively, the rate constant of the back reaction might be underestimated. In our previous study ${ }^{7}$, although the concentration of $\mathrm{H}^{+}$was extremely low compared to the phosphate concentration, the protonated surface sites were found to dominate over the $\mathrm{pH}$ range 6.0-8.0. As such, it can be concluded that the protonation of surface sites competed effectively with the reaction between phosphate and surface sites and, as such, this reaction should be included in any mechanistically-oriented modeling approach.

The rate at which phosphate is removed by Fe(III) is critical in determining the fate, forms and bioavailability of phosphorus in natural water or wastewater at circumneutral $\mathrm{pH}$. In this study, two distinct aqueous systems were used to investigate the kinetics of phosphate removal by iron. First, we investigated the kinetics of phosphate adsorption by preformed HFO (PF-HFO) at circumneutral $\mathrm{pH}$ 6.0-8.0, in which millimolar lever of $\mathrm{Fe}$ (III) was added to buffer solution to initially form PF-HFO, followed by the subsequent addition of phosphate to the PF-HFO dispersion. Subsequently, we analyzed the kinetics of in situ phosphate removal by adding Fe(III) directly into phosphate solutions in the form of a ferric salt. In this case, phosphate was removed from solution by adsorption to in situ formed hydrous ferric oxide (ISF-HFO).

The data sets obtained in the two types of studies outlined above were then described using traditional empirical models including the pseudo-second-order model ${ }^{23}$, the Elovich model ${ }^{17-19}$, and the intra-particle diffusion model ${ }^{20,21}$. Additionally, the ability of the more mechanistically-based surface complexation kinetic models (SCKMs) for the description of phosphate removal by both PF-HFO and ISF-HFO were investigated.

\section{Results and Discussion}

Phosphate removal efficiency under various conditions. The rate and extent of phosphate removal were investigated as a function of both initial phosphate concentration and the solution $\mathrm{pH}$. The various conditions under which phosphate removal was examined are shown in Supplementary Table S1.

In the PF-HFO adsorption process, relatively rapid phosphate adsorption was observed in the initial $60 \mathrm{~min}$ followed by slower phosphate uptake. The higher the initial phosphate concentration used, the larger the absolute amount but the smaller the proportion of phosphate was adsorbed by $1 \mathrm{mM}$ PF-HFO. The extent of adsorption was due to the relatively high availability of sites on the PF-HFO surface for phosphate adsorption when a higher solute concentration gradient was used. An increase of $\mathrm{pH}$ was found to decrease the phosphate adsorption efficiency by PF-HFO dramatically, due to the change in the nature of the surface species involved in phosphate adsorption. This effect has been investigated previously and is accounted for by the molecular models used to describe phosphate adsorption in that study ${ }^{7}$.

At each condition investigated in this study, the efficiency of phosphate removal using Fe(III) added directly into phosphate solutions (in situ process) was significantly higher than that when the same concentration of phosphate was added to the PF-HFO suspension formed by same amount of iron. Since the production of strengite $\left(\mathrm{FePO}_{4}(\mathrm{~s})\right)$ to achieve high phosphate removal efficiencies has been shown to be extremely unlikely if $\mathrm{Fe}(\mathrm{III}) \mathrm{salts}$ are used, the in situ phosphate removal process can be considered an alternative adsorption process to that of phosphate adsorption to PF-HFO. In the process of phosphate adsorption onto PF-HFO, much of the HFO would form in the absence of phosphate, making internal sites unavailable for binding ${ }^{6}$. However, the in situ formed solid with an open structure ${ }^{6}$ provides the advantage of a greater number of surface sites than that in the case for preformed HFO. In addition to the greater phosphate uptake capacity, the rate of phosphate removal in the in situ process was much higher than that in the PF-HFO case, with most of the phosphate removal being completed in the first $30 \mathrm{~min}$. In a manner similar to that of the PF-HFO adsorption process, the amount of phosphate removed by a particular concentration of $\mathrm{Fe}(\mathrm{III})$ in the in situ removal process increased with increasing initial phosphate concentration. Unlike the PF-HFO adsorption process, however, the phosphate removal efficiency was not sensitive to changes in solution $\mathrm{pH}$. The reason for this very distinct difference will be discussed below.

Traditional kinetic models of phosphate adsorption by preformed and in situ formed hydrous ferric oxide. To evaluate the effects of the initial phosphate concentration and $\mathrm{pH}$ on phosphate adsorption rates, a pseudo-second-order model was used to describe the kinetics of phosphate adsorption by PF-HFO.

Supplementary Fig. S1 demonstrates that a pseudo-second-order model provides a good description of the results obtained for the different initial phosphate concentrations $(0.25 \mathrm{mM}, 0.5 \mathrm{mM}$ and $1 \mathrm{mM})$ and $\mathrm{pH}$ values $(6.0,7.0$, and 8.0$)$ in our study. The corresponding model parameters calculated from the intercepts and slopes of these lines, including $q_{e}, k_{s e c}$, and $h$, are summarized in Supplementary Table S2. From this table, the effect of initial phosphate concentration and $\mathrm{pH}$ on the phosphate adsorption efficiency is quantified using $q_{e}$, which increases with increasing initial phosphate concentration and decreasing $\mathrm{pH}$. Others have concluded ${ }^{24,25}$ that phosphate adsorption can be described by the physical diffusion of phosphate in solution, in the liquid film surrounding particles and within the pores of the PF-HFO particles, followed by chemical reaction between the phosphate species and the PF-HFO surface sites. As such, the results determined here for the effect of $\mathrm{pH}$ on the rate constants suggests that the initial adsorption rate was determined, for the most part, by fast chemical reactions between phosphate and surface sites, while the rates at later times were most likely determined by physical diffusion effects. 
In the in situ phosphate removal process, phosphate may either interact with added ferric cations and form distinct assemblages of strengite $\left(\mathrm{FePO}_{4}(\mathrm{~s})\right)$, or it may be adsorbed by in situ formed HFO. We have noted earlier that the conditions in wastewater treatment are not particularly suited to strengite formation and, as such, phosphate adsorption is the most likely mechanism of phosphate removal. Therefore, to evaluate the rate of in situ phosphate removal, the pseudo-second-order model was also used to describe the kinetics of phosphate removal. The model results are shown in Supplementary Fig. S2, and the model parameters derived from the model fits are presented in Supplementary Table S3. As with the PF-HFO adsorption process, the application of the pseudo-second-order model to the description of the in situ data is successful. However, the parameters are significantly different to those obtained for the PF-HFO adsorption process. It is obvious that phosphate removal via the in situ process is much faster than that for the PF-HFO adsorption process for any particular condition, resulting in higher phosphate removal efficiencies. An increase in the initial concentration of phosphate significantly reduces the phosphate removal rates $\left(k_{s e c}\right)$, but a change in $\mathrm{pH}$ does not significantly impact rates of phosphate removal $\left(k_{s e c}\right)$. The decrease of $k_{s e c}$ with increasing initial concentration of phosphate is a commonly known fact (the higher the initial concentration, the longer time is required to reach equilibrium). However, the influence of $\mathrm{pH}$ on the value of $k_{s e c}$ has not been theoretically investigated, which may be due to its complexity. It is suspected that the phosphate removal rates via an in situ process in this study are principally dependent on the physical factors associated with the configuration rather than the chemical reactions between phosphate and the sorbing phase.

The Elovich equation was also used to model the removal of phosphate by PF-HFO with reasonable linear relationships between $\ln t$ and $q_{t}$ being obtained for the various sets of phosphate removal data (Supplementary Fig. S3). The Elovich coefficients calculated from the intercepts and slopes of these straight lines are shown in Supplementary Table S3. Generally, the initial adsorption rate $A$ decreased and the desorption constant $B$ increased with increasing $\mathrm{pH}$ (except for the unusually low $B$ value in expt no. 6) and both $A$ and $B$ decreased as the initial phosphate concentration increased (except for the unusual $A$ values in expt nos 5 and 9). Although a variety of explanations have been provided ${ }^{25}$ for the observed changes in the Elovich model parameters with changes in $\left[\mathrm{PO}_{4}{ }^{3-}\right]_{\mathrm{T}}$ and $\mathrm{pH}$, a definitive mechanism providing a rationalization for these changes has not yet been presented. Plazinski et al. ${ }^{24}$ concluded that both the Elovich model and the pseudo-second-order model provide similar descriptions of phosphate adsorption kinetics and are special forms of the "generalized-Elovich" model proposed by Rudzinski and Plazinski ${ }^{26}$.

The Elovich equation was unsuccessful in describing the kinetics of in situ phosphate removal as indicated by the poor fit of $q_{t}$ against $t$ in Supplementary Fig. S4. Because the Elovich equation neglects desorption, $q_{t}$ would be expected to continually increase at extended adsorption times. As such, the Elovich equation is clearly inappropriate for description of in situ phosphate removal process where equilibrium is nearly attained.

The intra-particle diffusion model was applied in order to assess the importance of intra-particle diffusion in the kinetics of phosphate adsorption by PF-HFO and in situ phosphate removal. As found for the Elovich model, the intra-particle diffusion model was only suitable for describing phosphate adsorption by PF-HFO with reasonable fits of Eq. (7) to the phosphate adsorption data, especially at higher initial phosphate concentrations (Supplementary Fig. S5). The values of the intra-particle diffusion rate constant, $k_{i n t}$, obtained by plotting $q_{t}$ versus $t_{1 / 2}$ for various phosphate concentrations and $\mathrm{pH}$ values, are shown in Supplementary Table S4. Further, by assuming that PF-HFO assemblages consist of spherical particles, the diffusion coefficients for the intra-particle transport of aqueous phosphate species within the PF-HFO pores were calculated using Eq. $(1)^{27}$ and Eq. $(2)^{28}$,

$$
\begin{gathered}
t_{1 / 2}=\frac{1}{k_{\mathrm{sec}} q_{e}} \\
D=\frac{0.03 \times R^{2}}{t_{1 / 2}}
\end{gathered}
$$

where $D\left(\mathrm{~cm}^{2} \mathrm{~min}^{-1}\right)$ is the diffusion coefficient, $R(\mathrm{~cm})$ represents the average radius of PF-HFO (and is equal to $6.26 \times 10^{-4} \mathrm{~cm}$ which was calculated using the data in our previous study $\left.{ }^{7}\right)$, and $t_{1 / 2}(\mathrm{~min})$ is the half time of phosphate adsorption.

As shown in Supplementary Fig. S5, none of the plots passed through the origin, indicating that intra-particle diffusion was not the rate-limiting step for phosphate adsorption by PF-HFO ${ }^{20,29}$. Also, the correlation coefficients $\left(r^{2}\right)$ of the fits varied significantly with the goodness of the fits improving as the initial phosphate concentration increased. These results suggest that the intra-particle diffusion effects were more important at higher initial phosphate concentrations, with the intra-particle diffusion rate constants, $k_{\text {int }}$, generally increasing with increasing initial phosphate concentrations.

In addition, as shown in Supplementary Table S4, although the diffusion coefficient $D$ increased, the half time of phosphate adsorption, $t_{1 / 2}$, had the opposite trend and decreased as the initial phosphate concentration and $\mathrm{pH}$ decreased. Both $D$ and $t_{1 / 2}$ were calculated using the parameters from the pseudo-second-order model, with $D$ being found to be on the order of $10^{-8} \mathrm{~cm}^{2} \mathrm{~min}^{-1}$. As such, intra-particle phosphate diffusion is not important in the early stage of phosphate adsorption, although it would play an important role in the later stages of phosphate adsorption ${ }^{30,31}$ and could result in the time for phosphate removal varying for several days (as indeed has been previously observed ${ }^{7}$ ).

Data obtained for in situ phosphate removal were poorly described by the intra-particle diffusion model (Fig. S6).

Surface complexation kinetic models for phosphate adsorption by PF-HFO. According to the rate expressions derived earlier for the surface complexation reactions, while the rate constants should vary with 


\begin{tabular}{|l|c|c|c|c|c|c|}
\hline \multirow{2}{*}{ Model parameters } & \multicolumn{2}{|c|}{$\mathbf{p H}=\mathbf{6}$} & \multicolumn{2}{c|}{$\mathbf{p H}=\mathbf{7}$} & \multicolumn{2}{c|}{$\mathbf{p H}=\mathbf{8}$} \\
\cline { 2 - 7 } & SCKM-1 & SCKM-2 & SCKM-1 & SCKM-2 & SCKM-1 & SCKM-2 \\
\hline$k_{1}{ }^{\prime}\left(\mathrm{min}^{-1}\right)$ & - & 0.0776 & - & 0.0856 & - & 0.0947 \\
\hline$k_{2}\left(\mathrm{~min}^{-1}\right)$ & - & 0.00329 & - & 0.00239 & - & 0.00381 \\
\hline$k_{a}{ }^{\prime}\left(\mathrm{mM}^{-1} \mathrm{~min}^{-1}\right)$ & 0.205 & 0.274 & 0.129 & 0.149 & 0.0386 & 0.0680 \\
\hline$k_{d}\left(\mathrm{~min}^{-1}\right)$ & 0.0279 & - & 0.0470 & - & 0.0309 & - \\
\hline PZC & - & 7.37 & - & 8.55 & - & 9.39 \\
\hline
\end{tabular}

Table 1. Model parameters for SCKM-1 and SCKM-2 at different $\mathbf{p H}$ values ${ }^{\mathrm{a}}{ }^{\mathrm{a}}{ }^{\mathrm{T}}$ The model parameters were obtained when the influence of initial phosphate concentration was neglected.

$\mathrm{pH}$, a correlation between the initial concentration of phosphate and the rate constants is not expected. As such, we initially modeled the data sets at different initial concentrations of phosphate using only one set of rate constants in both the SCKM-1 and SCKM-2 models. The results of these initial analyses are shown in Supplementary Fig. S7 and the model parameters are presented in Table 1. Perhaps not surprisingly, given the larger number of fitting parameters, the SCKM-2 model is seen to provide a better fit to the data than the SCKM-1 model. The desorption rate constants $k_{2}$ derived from the SCKM-2 fitting were extremely low at every $\mathrm{pH}(6.0-8.0)$ and, as such, are not shown in Table 1 . The fact that phosphate desorption is insignificant means that the SCKM-2 model is, in essence, equivalent to the SCKM-3 model under the conditions used in this study. From Table 1, the adsorption rate constant $k_{1}{ }^{\prime}$ derived from the SCKM-2 model $\left(0.0680-0.274 \mathrm{mM}^{-1} \mathrm{~min}^{-1}\right)$ is higher than the same constant derived using the SCKM-1 model $\left(0.0386-0.205 \mathrm{mM}^{-1} \mathrm{~min}^{-1}\right)$. This means that neglecting the protonation of surface sites led to an underestimation of the adsorption rate constant. It is also noteworthy that $k_{1}{ }^{\prime}$ decreased with increasing $\mathrm{pH}$ for both the SCKM-1 and SCKM-2 models while the protonation reaction rate constant $k_{a}{ }^{\prime}$ in SCKM-2 (0.0776-0.0947 $\left.\mathrm{mM}^{-1} \mathrm{~min}^{-1}\right)$ increased over the $\mathrm{pH}$ range 6.0-8.0. This result suggests that the deprotonation reaction is an important determinant of phosphate adsorption to PF-HFO.

With regard to the influence of initial phosphate concentration on the phosphate adsorption kinetics, the three models were fit to the various data sets available. The solid and dotted lines in Supplementary Fig. S8 represent the results of the application of SCKM-1 and SCKM-2 models while the dotted lines in Supplementary Fig. S9 represent the results of SCKM-3 modeling. It is clear from these results that both the SCKM-2 and SCKM-3 models describe the phosphate adsorption onto PF-HFO quite well, while SCKM-1, with a much shorter equilibrium time, demonstrates larger errors. The parameter values obtained for the different models are shown in Table 2, with both the values for the phosphate adsorption rate constants, $k_{a}{ }^{\prime}$, for the SCKM-2 and SCKM-3 models evident with the values being higher than the constant determined using the SCKM-1 model.

Since the SCKM-2 and SCKM-3 models provide a better description of phosphate adsorption than the SCKM-1 model, further analysis of the results obtained through use of the SCKM-2 and SCKM-3 models is provided below.

It is obvious that the adsorption rate constant $k_{a}^{\prime}$ decreases dramatically with increasing in $\mathrm{pH}$. To quantify this dependency further, the function $k_{a}^{\prime}=k_{a}\left[\mathrm{H}^{+}\right]^{n}$ can be transformed as:

$$
\log k_{a}^{\prime}=\log k_{a}-n \times \mathrm{pH}
$$

Thus a plot of the $\log k_{a}{ }^{\prime}$ versus $\mathrm{pH}$ should be a straight line with a slope of $-n$ and a y-intercept of the $\log k_{a}$ (the intrinsic adsorption rate constant). Linear fits to the model parameters obtained using the SCKM-2 model (Table 1) are shown in Fig. 1 . The $\log k_{a}$ and $n$ values obtained are 1.266 and 0.302 , respectively, with $r^{2}=0.982$. Linear fitting data for the model parameters obtained using SCKM-3 (Table 2) are given in Table 3 (and the fitting figures are shown in Supplementary Fig. S10), from which a range of $\log k_{a}$ from 0.787 to 1.420 , with an average value $1.06 \pm 0.33$ and a range of $\mathrm{n}$ of $0.212-0.316$, with an average value $0.255 \pm 0.054$ were obtained. In general, the $r^{2}$ values are above 0.84 , indicating good agreement between our model and the observed data. Thus, the adsorption rate constant for phosphate adsorbed onto PF-HFO can be deduced at other $\mathrm{pH}$ values, using Eq. 3 with constants $\log k_{a}=1.06 \pm 0.33$ and $\mathrm{n}=0.255 \pm 0.054$.

According to Hiemstra et al. ${ }^{32}$, the point of zero charge can be simplified as $\log K_{H}=$ PZC. Thus,

$$
\mathrm{PZC}=\log _{10} \frac{k_{a}}{k_{d}}=\log _{10} \frac{k_{a}^{\prime}}{k_{d}\left[\mathrm{H}^{+}\right]}=\log _{10} \frac{k_{a}^{\prime}}{k_{d}}+\mathrm{pH}
$$

Once $k_{a}{ }^{\prime}$ and $k_{d}$ have been estimated using the surface complexation kinetic models, PZC can be calculated using Eq. (4). The results deduced by this approach shown in Tables 1 and 2. The range of PZC values obtained is 6.19-9.91, with an average value $8.23 \pm 1.02$, which is close to the value for HFO determined by Hiemstra and Riemsdijk $(\mathrm{PZC}=8.1)^{33}$.

In the surface complexation kinetic models, the phosphate adsorption rate constant $k_{a}^{\prime}$ was observed to decrease with increasing initial phosphate concentration (Fig. 2). A possible reason for this relationship could be the neglect of physical diffusion. Although the experimental conditions in the studies described here including temperature and stirring rate, have been constantly maintained, the initial concentration of phosphate would influence the diffusion rate and, as a result, influence the phosphate adsorption rate.

Surface complexation kinetic models for in situ phosphate removal by Fe(III). As mentioned above, the reason for the greater extent of phosphate removal by in situ formed hydrous ferric oxide (compared 


\begin{tabular}{|c|c|c|c|c|c|c|c|c|c|}
\hline & \multicolumn{3}{|c|}{$\left[\mathrm{PO}_{4}{ }^{3-}\right]_{\mathrm{T}}=0.25 \mathrm{mM}$} & \multicolumn{3}{|c|}{$\left[\mathrm{PO}_{4}{ }^{3-}\right]_{\mathrm{T}}=0.50 \mathrm{mM}$} & \multicolumn{3}{|c|}{$\left[\mathrm{PO}_{4}{ }^{3-}\right]_{\mathrm{T}}=1.0 \mathrm{mM}$} \\
\hline & SCKM-1 & SCKM-2 & SCKM-3 & SCKM-1 & SCKM-2 & SCKM-3 & SCKM-1 & SCKM-2 & SCKM-3 \\
\hline \multicolumn{10}{|l|}{$\mathrm{pH}=6$} \\
\hline$k_{1}^{\prime}\left(\min ^{-1}\right)$ & - & 0.0674 & 0.0657 & - & 0.0683 & 0.0675 & - & 0.0678 & 0.119 \\
\hline$k_{2}\left(\min ^{-1}\right)$ & - & 0.0122 & 0.000604 & - & 0.0112 & 0.00148 & - & 0.0168 & 0.0776 \\
\hline$k_{a}{ }^{\prime}\left(\mathrm{mM}^{-1} \min ^{-1}\right)$ & 0.433 & 0.519 & 0.508 & 0.242 & 0.285 & 0.278 & 0.134 & 0.235 & 0.214 \\
\hline$k_{d}\left(\min ^{-1}\right)$ & 0.0177 & 0.0029 & - & 0.0323 & 0.00457 & - & 0.029 & 0.00264 & - \\
\hline$C_{s s}(\mathrm{mM} \mathrm{mM})^{-1 \mathrm{~b}}$ & 0.45 & 0.45 & 0.45 & 0.45 & 0.45 & 0.45 & 0.45 & 0.45 & 0.45 \\
\hline$C_{s s}(\mathrm{mM} \mathrm{mM})^{-1 \mathrm{c}}$ & 0.919 & 1.03 & 0.807 & 1.25 & 1.09 & 0.958 & 1.04 & 0.809 & 0.694 \\
\hline PZC & - & 6.74 & 8.04 & & 6.79 & 7.66 & & 6.61 & 6.19 \\
\hline \multicolumn{10}{|l|}{$\mathrm{pH}=7$} \\
\hline$k_{1}^{\prime}\left(\min ^{-1}\right)$ & - & 0.0788 & 0.0802 & - & 0.108 & 0.106 & - & 0.219 & 0.176 \\
\hline$k_{2}\left(\min ^{-1}\right)$ & - & 0.00489 & 0.000485 & - & 0.00403 & 0.00166 & - & 0.0137 & 0.00614 \\
\hline$k_{a}^{\prime}\left(\mathrm{mM}^{-1} \min ^{-1}\right)$ & 0.241 & 0.276 & 0.275 & 0.192 & 0.232 & 0.229 & 0.0779 & 0.170 & 0.151 \\
\hline$k_{d}\left(\min ^{-1}\right)$ & 0.0382 & 0.00223 & - & 0.0552 & 0.00138 & - & 0.0432 & 0.00288 & - \\
\hline$C_{s s}(\mathrm{mM} \mathrm{mM})^{-1 \mathrm{~b}}$ & 0.45 & 0.45 & 0.45 & 0.45 & 0.45 & 0.45 & 0.45 & 0.45 & 0.45 \\
\hline$C_{s s}(\mathrm{mM} \mathrm{mM})^{-1 \mathrm{c}}$ & 1.72 & 1.33 & 1.14 & 2.31 & 1.59 & 1.44 & 1.42 & 1.28 & 0.931 \\
\hline PZC & & 8.21 & 9.22 & & 8.43 & 8.81 & & 8.20 & 8.46 \\
\hline \multicolumn{10}{|l|}{$\mathrm{pH}=8$} \\
\hline$k_{l}^{\prime}\left(\min ^{-1}\right)$ & - & 0.0598 & 0.0984 & - & 0.0677 & 0.0579 & - & 0.0398 & 0.195 \\
\hline$k_{2}\left(\min ^{-1}\right)$ & - & 0.0168 & 0.00121 & - & 0.0127 & 0.0026 & - & 0.0256 & 0.00671 \\
\hline$k_{a}{ }^{\prime}\left(\mathrm{mM}^{-1} \mathrm{~min}^{-1}\right)$ & 0.152 & 0.214 & 0.191 & 0.0499 & 0.0705 & 0.0847 & 0.0227 & 0.0255 & 0.0715 \\
\hline$k_{d}\left(\min ^{-1}\right)$ & 0.0470 & 0.0175 & - & 0.0275 & 0.00462 & - & 0.0279 & 0.0108 & - \\
\hline$C_{s s}(\mathrm{mM} \mathrm{mM})^{-1 \mathrm{~b}}$ & 0.45 & 0.45 & 0.45 & 0.45 & 0.45 & 0.45 & 0.45 & 0.45 & 0.45 \\
\hline$C_{s s}(\mathrm{mM} \mathrm{mM})^{-1 \mathrm{c}}$ & 3.68 & 3.06 & 1.85 & 4.26 & 3.24 & 2.03 & 3.29 & 3.07 & 2.37 \\
\hline PZC & & 8.55 & 9.91 & & 8.73 & 9.35 & & 8.19 & 9.46 \\
\hline
\end{tabular}

Table 2. Model parameters for SCKM-1, SCKM-2, and SCKM-3 at different pH values and different initial phosphate concentrations ${ }^{\mathbf{a}}$. The model parameters were obtained when the influence of initial phosphate

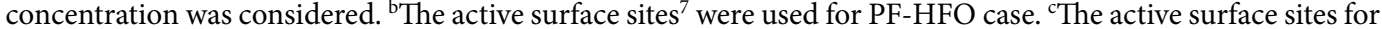
ISF-HFO case were determined by using the rate constants obtained in the PF-HFO case.

\begin{tabular}{|l|c|c|c|c|}
\hline & {$\left[\mathbf{P O}_{4}{ }^{3-}\right]_{\mathrm{T}}=\mathbf{0 . 2 5} \mathbf{~ m M}$} & {$\left[\mathbf{P O}_{4}{ }^{3-}\right]_{\mathrm{T}}=\mathbf{0 . 5 0} \mathbf{~ m M}$} & {$\left[\mathbf{P O}_{4}{ }^{3-}\right]_{\mathrm{T}}=\mathbf{1 . 0} \mathbf{m M}$} & Ave (mM) \\
\hline $\log k_{a}$ & 0.962 & 1.420 & 0.787 & $1.06 \pm 0.327$ \\
\hline$n$ & 0.212 & 0.316 & 0.238 & $0.255 \pm 0.054$ \\
\hline$r^{2}$ & 0.978 & 0.847 & 0.957 & - \\
\hline
\end{tabular}

Table 3. Linear fitting data of adsorption constants in SCKM-3.

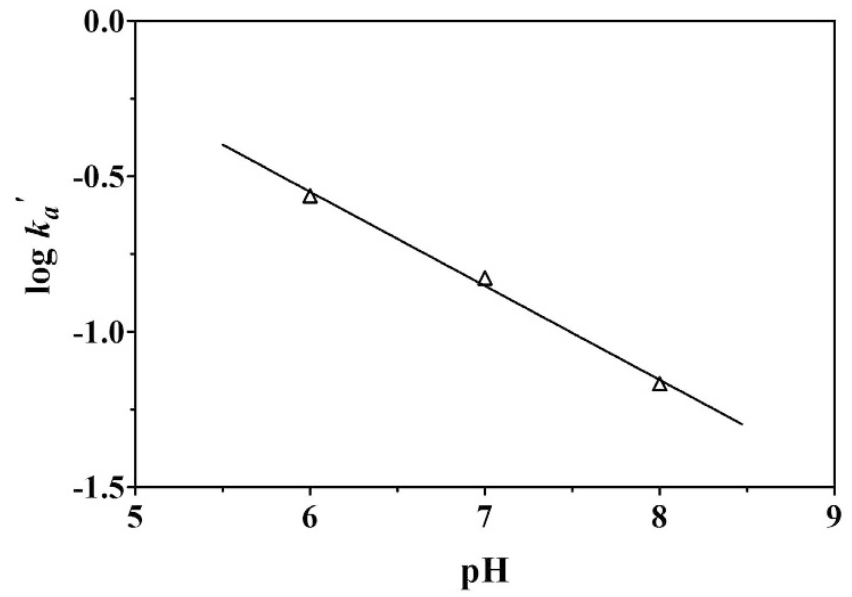

Figure 1. Linear dependence of $\log k_{a}^{\prime}$ values on $\mathrm{pH}$ determined from SCKM-2 fitting. 


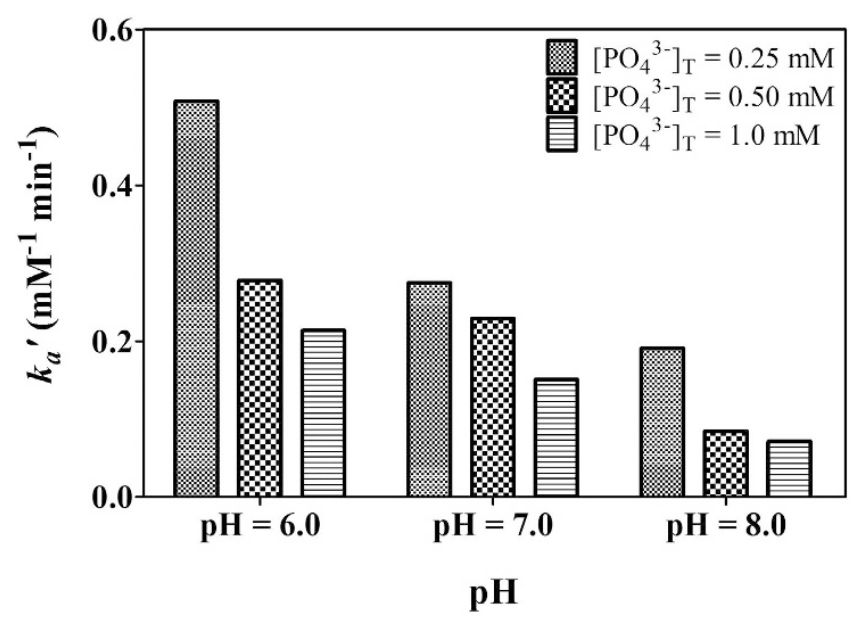

Figure 2. Values of phosphate adsorption rate constant $k_{a}$ for particular initial phosphate concentrations and $\mathrm{pH}$.

to preformed hydrous ferric oxide) is the greater number of active surface sites on the in situ formed solid than on the preformed HFO (the concentration of active surface sites (Css) was $0.45 \mathrm{mM}(\mathrm{mM} \mathrm{Fe})^{-1}$ in our previous $\operatorname{study}^{7}$ ). To quantify the amount of active surface sites on the in situ formed solid, we used the surface complexation kinetic models, with the parameters presented in Table 2, to evaluate the variation of Css. The results of these calculations are presented in Table 2. The fits using SCKM-1, SCKM-2, and SCKM-3 for in situ phosphate removal by $\mathrm{Fe}$ (III) are shown in Fig. 3. It was observed that all three of the surface complexation models could describe in situ phosphate removal by Fe(III) quite well. As shown in Table 2, the average values of Css for $\mathrm{pH}=6.0,7.0$ and 8.0 are $0.955 \pm 0.170,1.46 \pm 0.39$, and $2.98 \pm 0.78 \mathrm{mM}(\mathrm{mM} \mathrm{Fe})^{-1}$, respectively, which are larger than the value of $0.45 \mathrm{mM}(\mathrm{mM} \mathrm{Fe})^{-1}$ obtained for PF-HFO. However, as initial phosphate concentration at $\mathrm{pH}$ 6.0-8.0 was increased, the values of Css did not increase accordingly. The rate of HFO polymer formation will be much faster than that of phosphate adsorption by HFO. Hence, it is not surprising that a slight increase in phosphate concentration had little impact on the surface site concentration. In solution, when the iron atom was present as hydrated $\mathrm{Fe}\left(\mathrm{H}_{2} \mathrm{O}\right)_{6}{ }^{3+}$, the value of $C s s$ would reach its limits of $6 \mathrm{mM}([\mathrm{Fe}], \mathrm{mM})^{-1}$, and for solid HFO, the in air value of Css would be $3 \mathrm{mM}([\mathrm{Fe}], \mathrm{mM})^{-1}$ according to stoichiometric composition. However, for a 1-nm cube particle of HFO in solution, the value of Css was calculated to be $4.5 \mathrm{mM}([\mathrm{Fe}], \mathrm{mM})^{-16}$. In this study, the values of Css for in situ formed HFO increased with increasing $\mathrm{pH}$ and reached $2.98 \pm 0.78 \mathrm{mM}([\mathrm{Fe}], \mathrm{mM})^{-1}$ at $\mathrm{pH}=8.0$, which is close to the value determined by Smith et al. ${ }^{6}$ for 2 -nm cube particles.

A general conclusion of this study is that the kinetics of interaction between phosphate and $\mathrm{Fe}(\mathrm{III})$ in solution was not adequately described by traditional kinetic expressions (e.g. the pseudo-second order and the Elovich equations). However, they could be adequately described by models incorporating the acid-base chemistry of surface sites, proton-phosphate competition for surface sites and phosphate surface complexation. The more molecular-based kinetics models (SCKMs) investigated in this study can be promising to understand the phosphate removal by $\mathrm{Fe}(\mathrm{III})$, considering that it is a challenge to elucidate the realistic system by the traditional empirical models. Additionally, the rate of phosphate removal by $\mathrm{Fe}$ (III) was affected by the manner of adding $\mathrm{Fe}$ (III). This can be achieved in phosphate wastewater treatment by ensuring that iron salts are added in situ into the wastewater such that more active surface sites on HFO are produced to obtain a higher phosphate removal rate and efficiency. However, the kinetic models and rate constants developed in our study were investigated in the simulated waters containing simple inorganic matrices without the addition of organic compounds. In natural water or wastewater, various organic compounds could complex both Fe(III), and the formed Fe species, which would also affect the formation of HFO and further affect the kinetics of phosphate removal. These effects would need further investigation before the application of the developed models in natural water or wastewater.

\section{Methods}

Analytical grade reagents were used in all cases and purchased from Sigma-Aldrich unless otherwise stated. All solutions were prepared using $18 \mathrm{M} \Omega \mathrm{cm}$ ultrapure Milli-Q (MQ) water and stored in the dark at $4{ }^{\circ} \mathrm{C}$ when not in use. All glassware and plasticware were soaked in $5 \% \mathrm{v} / \mathrm{v} \mathrm{HCl}$ for several days and rinsed thoroughly with $\mathrm{MQ}$ water before use. All experiments were performed under conditions in which light was minimized to avoid Fe(III) reduction by wrapping the reaction vessel with dark cloth at $22 \pm 1{ }^{\circ} \mathrm{C}$.

The $\mathrm{pH}$ of all solutions used was carefully controlled with an appropriate buffer (10 mM MES (SigmaUltra) for pH 6.0-6.5 and $10 \mathrm{mM}$ MOPS (SigmaUltra) for $\mathrm{pH}$ 7.0-8.0). Both MES and MOPS are non-complexing agents ${ }^{34}$ and are unlikely to influence the behavior of other solution constituents ${ }^{7}$. All buffer solutions initially contained $2.0 \mathrm{mM} \mathrm{NaHCO}_{3}$ and $100 \mathrm{mM} \mathrm{NaCl}$ and were prepared one week prior to the commencement of each experiment in order to ensure that equilibrium was reached between the buffer solutions and the atmosphere. The chosen buffers maintained solution $\mathrm{pH}$ within $\pm 0.02 \mathrm{pH}$ units of the desired value during the course of each experiment. $\mathrm{pH}$ was measured using a HANNA $211 \mathrm{pH}$ meter combined with a glass electrode and $\mathrm{Ag} / \mathrm{AgCl}$ reference. NIST-traceable buffer solutions ( $\mathrm{pH} 4.01,7.01$ and 10.01) were used to calibrate the electrode on the NBS scale. 

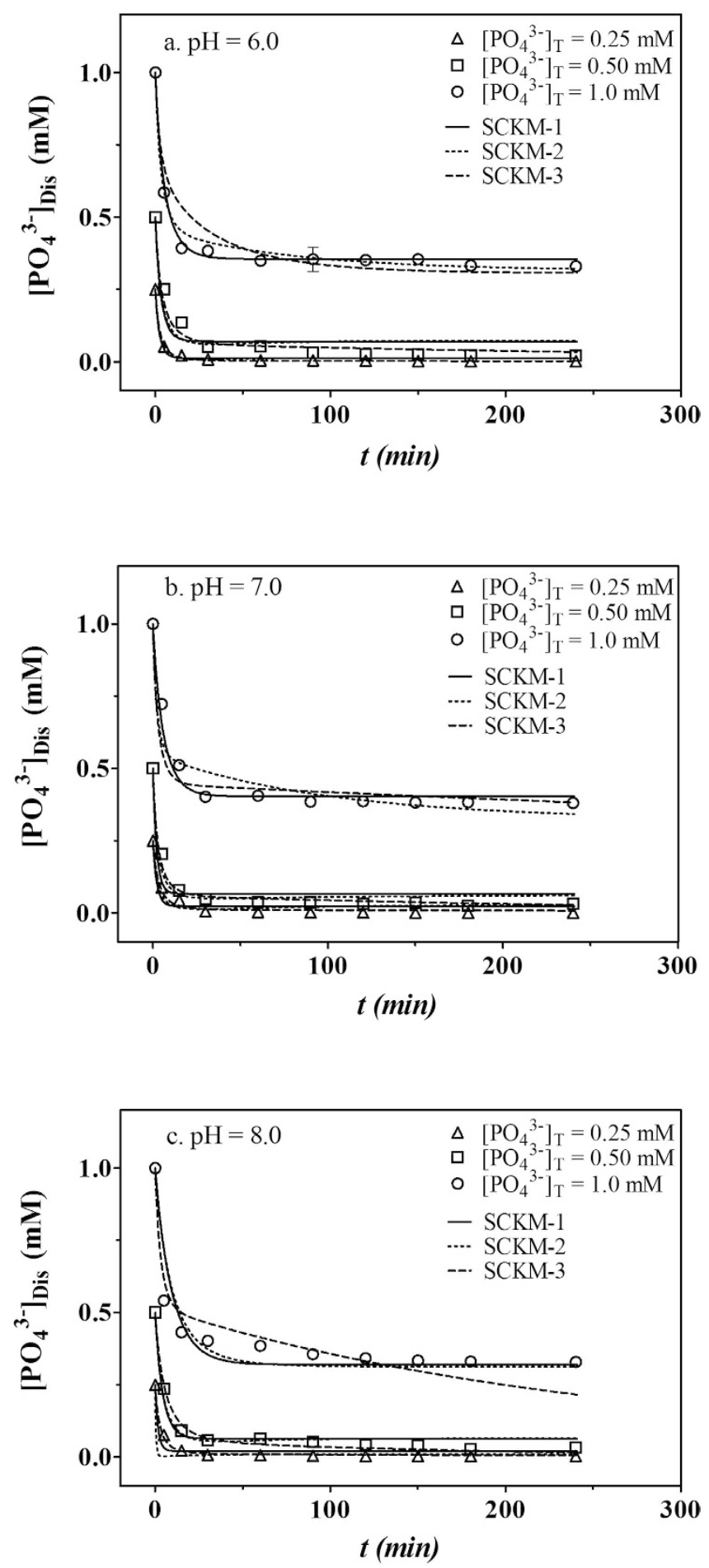

Figure 3. SCKM-1 (solid lines), SCKM-2 (dotted lines), and SCKM-3 (dashed lines) fits for $0.25 \mathrm{mM}(\triangle)$ ), $0.5 \mathrm{mM}(\square)$, and $1.0 \mathrm{mM}(\mathrm{O})$ phosphate in situ removal by $1 \mathrm{mM} \mathrm{Fe}(\mathrm{III})$ at $I=0.1 \mathrm{M} \mathrm{NaCl}$ and $\mathrm{pH}=6.0(\mathbf{a}), 7.0$ (b), and $8.0(\mathbf{c})$. Error bars are the standard error of the mean from triplicate experiments.

Any $\mathrm{pH}$ error due to ionic strength differences between the NIST standard buffers (pH 4.01, $I=0.05 ; \mathrm{pH} 7.01$, $I=0.13$; and $\mathrm{pH} 10.01, I=0.05)$ and experimental solutions $(I \sim 0.1$ in this work) is minor and can be neglected.

A $100 \mathrm{mM} \mathrm{Fe}$ (III) stock solution was prepared by dissolving an appropriate amount of $\mathrm{FeCl}_{3}$ in $2 \mathrm{mM} \mathrm{HCl}$. A $1.0 \mathrm{M}$ phosphate stock solution was prepared by dissolving an appropriate amount of $\mathrm{NaH}_{2} \mathrm{PO}_{4}$ in $\mathrm{MQ}$ water. PF-HFO were prepared by adding $1 \mathrm{mM}$ Fe(III) into the particular buffer solution ( $\mathrm{pH}$ 6.0-8.0) with stirring at $25 \mathrm{rpm}$ and $\mathrm{pH}$ readjusted to the specific value required. Speciation calculations using the Visual Minteq 3.0 chemical equilibrium program ${ }^{35}$ indicated that essentially all $\mathrm{Fe}$ (III) would be precipitated as $\mathrm{HFO}$ at the various pH examined. 
Kinetics of phosphate adsorption by PF-HFO. To determine the rate of phosphate adsorbed by PF-HFO at different $\mathrm{pH}$ values, 5-min-aged pre-polymerized $\mathrm{HFO}$ containing $1 \mathrm{mM}$ Fe(III) was used as the PF-HFO. The desired phosphate concentration was mixed with $200 \mathrm{~mL}$ of $1 \mathrm{mM} \mathrm{Fe}$ (III)-containing PF-HFO in $500 \mathrm{~mL}$ conical flasks which were agitated on a shaker at a constant speed $(120 \mathrm{rpm})$. Samples were withdrawn at desired intervals and immediately filtered through $25 \mathrm{mM}$ diameter Millex $0.45 \mu \mathrm{m}$ pore size membrane filters. Adsorption of soluble phosphate on the filter membrane was found to be negligible. The dissolved phosphate concentration $\left(\left[\mathrm{PO}_{4}{ }^{3-}\right]_{\text {Dis }}\right)$ was measured using the ascorbic acid molybdate blue method, and the colored complex was detected using a Cary $50 \mathrm{UV}$-Vis spectrophotometer. The concentration of removed phosphate $\left(\left[\mathrm{PO}_{4}{ }^{3-}\right]_{\text {ads }}\right)$ is equal to the initial phosphate concentration $\left(\left[\mathrm{PO}_{4}{ }^{3-}\right]_{\mathrm{T}}\right)$ minus the dissolved phosphate concentration. Experiments were repeated in triplicate for the different initial phosphate concentrations $(0.25 \mathrm{mM}, 0.5 \mathrm{mM}$ and $1 \mathrm{mM})$ and $\mathrm{pH}$ values $(6.0,7.0$ and 8.0$)$.

Kinetics of in situ phosphate removal. To determine the phosphate removal capacity and rate for the in situ process, the desired concentrations of phosphate were first added to $200 \mathrm{~mL}$ buffer solutions in $500 \mathrm{~mL}$ conical flasks, and then $\mathrm{Fe}$ (III) was added from the $100 \mathrm{mM}$ stock solution such that the reaction mixture had an $\mathrm{Fe}(\mathrm{III})$ concentration of $1 \mathrm{mM}$. The flasks were agitated on a shaker at $180 \mathrm{rpm}$ for the initial $5 \mathrm{~min}$ and then at $120 \mathrm{rpm}$ for the remaining time. The approach to sample treatment and phosphate measurement was identical to that used in the investigation of PF-HFO described above. Experiments were repeated in triplicate for the different initial phosphate concentrations $(0.25 \mathrm{mM}, 0.5 \mathrm{mM}$, and $1 \mathrm{mM})$ and $\mathrm{pH}$ values $(6.0,7.0$, and 8.0$)$.

Traditional kinetic models of phosphate removal. The removal efficiencies $(E, \%)$ of phosphate and the sorption capacity $\left(q,([\mathrm{P}], \mathrm{mM}) \cdot([\mathrm{Fe}], \mathrm{mM})^{-1}\right)$ in the in situ process and the PF-HFO adsorption process were calculated from Eqs. (5) and (6):

$$
\begin{gathered}
E(\%)=\frac{\left[\mathrm{PO}_{4}{ }^{3-}\right]_{\mathrm{T}}-\left[\mathrm{PO}_{4}{ }^{3-}\right]_{\mathrm{Dis}}}{\left[\mathrm{PO}_{4}{ }^{3-}\right]_{\mathrm{T}}} \times 100 \\
q=\frac{\left[\mathrm{PO}_{4}{ }^{3-}\right]_{\mathrm{T}}-\left[\mathrm{PO}_{4}{ }^{3-}\right]_{\mathrm{Dis}}}{[\mathrm{Fe}]_{\mathrm{T}}}
\end{gathered}
$$

where $[\mathrm{Fe}]_{\mathrm{T}}$ (in $\mathrm{mM}$ of $\mathrm{Fe}$ ) denotes the total concentration of $\mathrm{HFO}$ in solution.

When treating phosphate adsorption as a second order process, the relationship of sorption capacity $\left(q_{t},([\mathrm{P}], \mathrm{mM})\right.$ $\left.([\mathrm{Fe}], \mathrm{mM})^{-1}\right)$ and adsorption time $(t, \mathrm{~min})$ can be linearly expressed $\mathrm{as}^{23}$ :

$$
\frac{t}{q_{t}}=\frac{1}{k_{\mathrm{sec}} q_{e}^{2}}+\frac{t}{q_{e}}
$$

where $k_{\text {sec }}\left(([\mathrm{Fe}], \mathrm{mM})([\mathrm{P}], \mathrm{mM})^{-1} \mathrm{~min}^{-1}\right)$ represents the second-order rate constant for phosphate adsorption and $q_{e}\left(([\mathrm{P}], \mathrm{mM})([\mathrm{Fe}], \mathrm{mM})^{-1}\right)$ is the sorption capacity at adsorption equilibrium. The initial adsorption rate $h$ $\left(([\mathrm{P}], \mathrm{mM})([\mathrm{Fe}], \mathrm{mM})^{-1} \mathrm{~min}^{-1}\right)$ may be calculated using the following equation ${ }^{23}$ :

$$
h=k_{\mathrm{sec}} q_{e}^{2}
$$

The Elovich model proposed by Roginsky and Zeldovich ${ }^{17}$ was also adopted to describe the kinetics of phosphate adsorption. The integral form of this equation can be depicted as ${ }^{18,19}$ :

$$
q_{t}=\frac{1}{B} \ln (1+A B t)
$$

where $A\left(([\mathrm{P}], \mathrm{mM})([\mathrm{Fe}], \mathrm{mM})^{-1} \mathrm{~min}^{-1}\right)$ is the initial sorption rate and $B\left(([\mathrm{Fe}], \mathrm{mM})([\mathrm{P}], \mathrm{mM})^{-1}\right)$ is the desorption constant. When $A B t \gg 1$, this equation can be linearized to:

$$
q_{t}=\frac{\ln A B}{B}+\frac{1}{B} t
$$

Recognizing that the kinetics of phosphate adsorption may be controlled by diffusion processes, Weber and Morris $^{20}$ and McKay and Poots ${ }^{21}$ introduced the intra-particle diffusion model:

$$
q_{t}=k_{\mathrm{int}} t^{1 / 2}+C
$$

where $C\left(([\mathrm{P}], \mathrm{mM})([\mathrm{Fe}], \mathrm{mM})^{-1}\right)$ is the intercept and $k_{\text {int }}\left(([\mathrm{P}], \mathrm{mM})([\mathrm{Fe}], \mathrm{mM})^{-1} \mathrm{~min}^{-1 / 2}\right)$ is the intra-particle diffusion rate constant.

One reversible reaction modeling process (SCKM-1). According to Langmuir ${ }^{36}$, adsorption can be regarded as a reversible process between the adsorbent and adsorbate. In our previous study, the adsorption of phosphate onto PF-HFO was conceptualized as a "surface complexation" reaction": 


$$
\mathrm{PO}_{4}^{3-}+\equiv \mathrm{FeOH}+\mathrm{nH}^{+} \underset{k_{b}}{\stackrel{k_{a}}{\rightleftharpoons}} \equiv \mathrm{FeH}_{\mathrm{n}} \mathrm{PO}_{4}^{(3-n)-}+\mathrm{H}_{2} \mathrm{O}
$$

where $k_{a}$ and $k_{d}$ represent the adsorption and desorption rate constants, $\mathrm{PO}_{4}{ }^{3-}$ represents the various possible solution-phase phosphate species (which are assumed to interchange rapidly), $\equiv \mathrm{FeOH}$ represents the active surface site on PF-HFO, which was determined to be $0.45 \mathrm{mM}([\mathrm{Fe}], \mathrm{mM})^{-1}$ in our previous study ${ }^{7}$ (though protonated or deprotonated forms may dominate depending upon the $\mathrm{pH}$ ), and $\equiv \mathrm{FeH}_{\mathrm{n}} \mathrm{PO}_{4}{ }^{\left({ }^{-}-\mathrm{n}\right)-}$ was considered to be representative of the phosphate "surface complex", which forms on the surface of HFO (and which is simplified to $\equiv \mathrm{FeP}$ below). It should be noted that the phosphate surface complex used in this study was semi-empirical and that the actual surface speciation of HFO was complicated and should be further investigated by ATR-FTIR and XAFS ${ }^{37}$.

By applying the mass action law to the reaction, the overall rate equation for adsorption can be expressed as follows:

$$
r=\frac{d[\equiv \mathrm{FeP}]}{d t}=r_{a}-r_{d}=k_{a}\left[\mathrm{PO}_{4}{ }^{3-}\right][\equiv \mathrm{FeOH}]\left[\mathrm{H}^{+}\right]^{n}-k_{d}[\equiv \mathrm{FeP}]
$$

where $r, r_{a}$ and $r_{d}$ represent the overall rate, the adsorption rate and the desorption rate, respectively and $n$ represents the number of protons associated with each "surface complex".

If the $\mathrm{pH}$ is constant during phosphate sorption, the overall rate equation may be simplified to:

$$
r=\frac{d[\equiv \mathrm{FeP}]}{d t}=r_{a}-r_{d}=k_{a}^{\prime}\left[\mathrm{PO}_{4}^{3-}\right][\equiv \mathrm{FeOH}]-k_{d}[\equiv \mathrm{FeP}]
$$

where $k_{a}^{\prime}=k_{a}\left[\mathrm{H}^{+}\right]^{n}$. When the initial concentration of phosphate, concentration of total active surface sites and concentration of occupied surface active sites $\equiv \mathrm{FeP}$ are represented as $C_{p}, C_{s}$, and $P_{a d s}$, respectively, the overall rate equation becomes:

$$
r=\frac{d P_{a d s}}{d t}=k_{a}^{\prime}\left(C_{p}-P_{a d s}\right)\left(C_{s}-P_{a d s}\right)-k_{d} P_{a d s}=k_{a}^{\prime} P_{a d s}^{2}-\left(k_{a}^{\prime} C_{p}+k_{a}^{\prime} C_{s}+k_{d}\right) P_{a d s}+k_{a}^{\prime} C_{p} C_{s}
$$

when $P_{a d s}=0$ at $t=0$, Eq. (11) yields:

$$
P_{a d s}=\frac{4 A / C\left[\exp \left(t C \sqrt{(B / C)^{2}-4 A / C}\right)-1\right]}{2\left\{B / C+\sqrt{(B / C)^{2}-4 A / C}-\left((B / C)-\sqrt{(B / C)^{2}-4 A / C}\right) \exp \left(t C \sqrt{(B / C)^{2}-4 A / C}\right)\right\}}
$$

where $A=k_{a}^{\prime} C_{p} C_{s}, B=-\left(k_{a}^{\prime} C_{p}+k_{a}^{\prime} C_{s}+k_{d}\right)$, and $C=k_{a}^{\prime}$. According to Eq. (16), $k_{a}{ }^{\prime}$ and $k_{d}$ can be obtained using the least square method.

Two reversible reactions modeling process (SCKM-2). We have previously shown that the protonation of surface sites occurs in parallel with the adsorption of phosphate ${ }^{7}$. Hence, surface site protonation:

$$
\equiv \mathrm{FeOH}+\mathrm{nH}^{+} \underset{k_{2}}{\stackrel{k_{1}}{\longrightarrow}} \equiv \mathrm{FeOH}_{\mathrm{n}+1}{ }^{n+}
$$

where $k_{1}$ and $k_{2}$ represent the protonation and deprotonation rate constants, and $\equiv \mathrm{FeOH}_{\mathrm{n}+1}{ }^{\mathrm{n}+}$ represents the protonated surface sites (shortened to $\equiv \mathrm{FeOH}^{+}$below) should also be considered when modeling phosphate adsorption.

If the $\mathrm{pH}$ is constant during phosphate sorption, the $\mathrm{pH}$ dependence of the process can be incorporated in the rate expression by use of the rate constant:

$$
k_{1}^{\prime}=k_{1}\left[\mathrm{H}^{+}\right]^{n}
$$

When $k_{1}{ }^{\prime}, k_{2}, k_{a}{ }^{\prime}$, and $k_{d}$ are all treated as unknown parameters requiring evaluation, the differential equations describing the kinetics of phosphate adsorption are:

$$
\begin{gathered}
\frac{d C_{s}}{d t}=-k_{1}^{\prime} C_{s}+k_{2} C_{s}^{\prime}-k_{a}^{\prime} C_{s} C_{p}+k_{d} P_{a d s} \\
\frac{d C_{s}^{\prime}}{d t}=k_{1}^{\prime} C_{s}-k_{2} C_{s}^{\prime} \\
\frac{d C_{p}}{d t}=-k_{a}^{\prime} C_{s} C_{p}+k_{d} P_{a d s} \\
\frac{d P_{a d s}}{d t}=k_{a}^{\prime} C_{s} C_{p}-k_{d} P_{a d s}
\end{gathered}
$$


where $C_{s}{ }^{\prime}$ represents the concentration of protonated surface sites present. As these differential equations cannot be solved analytically, we have used the numerical methods package in DynaFit ${ }^{38}$ to model the time dependent phosphate adsorption process in this study.

One reversible reaction and one irreversible reaction modeling process (SCKM-3). In our previous study ${ }^{7}$, we observed that the equilibrium constants for phosphate adsorption to PF-HFO were extremely high, which means that the adsorption rate is much higher than the desorption rate. As such, Eq. (8) can be rewritten as:

$$
\mathrm{PO}_{4}{ }^{3-}+\equiv \mathrm{FeOH} \stackrel{k_{a}^{\prime}}{\Longrightarrow} \equiv \mathrm{FeP}+\mathrm{H}_{2} \mathrm{O}
$$

and the differential equations describing the phosphate adsorption process simplified to:

$$
\begin{gathered}
\frac{d C_{s}}{d t}=-k_{1}^{\prime} C_{s}+k_{2} C_{s}^{\prime}-k_{a}^{\prime} C_{s} C_{p} \\
\frac{d C_{s}^{\prime}}{d t}=k_{1}^{\prime} C_{s}-k_{2} C_{s}^{\prime} \\
\frac{d C_{p}}{d t}=-k_{a}^{\prime} C_{s} C_{p} \\
\frac{d P_{a d s}}{d t}=k_{a}^{\prime} C_{s} C_{p}
\end{gathered}
$$

The DynaFit approach was again used to model the experimental data on phosphate adsorption kinetics obtained and to derive values for the parameters $k_{1}{ }^{\prime}, k_{2}$, and $k_{a}{ }^{\prime}$.

\section{References}

1. Fytianos, K., Voudrias, E. \& Raikos, N. Modelling of phosphorus removal from aqueous and wastewater samples using ferric iron. Environ. Pollut. 101, 123-130 (1998).

2. Ferreira, S. S., Marguti, A. L. \& Piveli, R. P. Physical-Chemical Process Optimization for Phosphorus Removal from Domestic Wastewater by Chemical Precipitation with Ferric Chloride. Eng. Sanit. Ambient. 13, 395-404 (2008).

3. Sisk, L., Benefield, L. \& Reed, B. Ortho-Phosphate Removal from a Synthetic Waste-Water Using Lime, Alum, and Ferric-Chloride. Separ. Sci. Technol. 22, 1471-1501 (1987).

4. Thistleton, J., Berry, T. A., Pearce, P. \& Parsons, S. A. Mechanisms of chemical phosphorus removal II - Iron(III) salts. Process Saf. Environ. 80, 265-269 (2002).

5. Galarneau, E. \& Gehr, R. Phosphorus removal from wastewaters: Experimental and theoretical support for alternative mechanisms. Water Res. 31, 328-338 (1997).

6. Smith, S., Takacs, I., Murthy, S., Daigger, G. T. \& Szabo, A. Phosphate complexation model and its implications for chemical phosphorus removal. Water Environ. Res. 80, 428-438 (2008).

7. Mao, Y., Ninh Pham, A., Xin, Y. \& David Waite, T. Effects of pH, floc age and organic compounds on the removal of phosphate by pre-polymerized hydrous ferric oxides. Sep. Purif. Technol. 91, 38-45 (2012).

8. Luengo, C., Brigante, M. \& Avena, M. Adsorption kinetics of phosphate and arsenate on goethite. A comparative study. J. Colloid. Interf. Sci. 311, 354-360 (2007).

9. Luengo, C., Brigante, M., Antelo, J. \& Avena, M. Kinetics of phosphate adsorption on goethite: Comparing batch adsorption and ATR-IR measurements. J. Colloid. Interf. Sci. 300, 511-518 (2006).

10. Mezenner, N. Y. \& Bensmaili, A. Kinetics and thermodynamic study of phosphate adsorption on iron hydroxide-eggshell waste. Chem. Eng. J. 147, 87-96 (2009).

11. Shi, Z.-1., Liu, F.-m. \& Yao, S.-h. Adsorptive removal of phosphate from aqueous solutions using activated carbon loaded with Fe(III) oxide. New Carbon Mater. 26, 299-306 (2011).

12. Song, X., Pan, Y., Wu, Q., Cheng, Z. \& Ma, W. Phosphate removal from aqueous solutions by adsorption using ferric sludge. Desalination 280, 384-390 (2011).

13. Zeng, L., Li, X. \& Liu, J. Adsorptive removal of phosphate from aqueous solutions using iron oxide tailings. Water Res. 38, 1318-1326 (2004).

14. Shang, C., Stewart, J. W. B. \& Huang, P. M. pH effect on kinetics of adsorption of organic and inorganic phosphates by short-range ordered aluminum and iron precipitates. Geoderma 53, 1-14 (1992).

15. Crosby, S. A., Millward, G. E., Butler, E. I., Turner, D. R. \& Whitfield, M. Kinetics of phosphate adsorption by iron oxyhydroxides in aqueous systems. Estuar. Coast. Shelf Sci. 19, 257-270 (1984).

16. Liu, Y. \& Shen, L. From Langmuir Kinetics to First- and Second-Order Rate Equations for Adsorption. Langmuir 24, 11625-11630 (2008).

17. Roginsky, S. Z. \& Zeldovich, J. Acta Physicochim. USSR 1, 554-594 (1934).

18. Taylor, H. A. \& Thon, N. Kinetics of Chemisorption1. J. Am. Chem. Soc. 74, 4169-4173 (1952).

19. Low, M. J. D. Kinetics of Chemisorption of Gases on Solids. Chem. Rev. 60, 267-312, doi: 10.1021/cr60205a003 (1960).

20. Weber, W. J. \& Morris, J. C. Kinetics of adsorption on carbon from solution. J. Sanit. Eng. Div. ASCE 89, 31-59 (1963).

21. McKay, G. \& Poots, V. J. P. Kinetics and diffusion processes in colour removal from effluent using wood as an adsorbent. J. Chem. Technol. Biot. 30, 279-292 (1980).

22. Shen, J. \& Duvnjak, Z. A reversible surface reaction model with an effectiveness factor and its application to sorption kinetics of cupric ions on corncob particles. Sep. Purif. Technol. 44, 69-77 (2005).

23. Ho, Y.-S. Review of second-order models for adsorption systems. J. Hazard. Mater. 136, 681-689 (2006).

24. Plazinski, W., Rudzinski, W. \& Plazinska, A. Theoretical models of sorption kinetics including a surface reaction mechanism: A review. Adv. Colloid Interfac. 152, 2-13 (2009).

25. Sen Gupta, S. \& Bhattacharyya, K. G. Kinetics of adsorption of metal ions on inorganic materials: A review. Adv. Colloid Interfac. $162,39-58(2011)$. 
26. Rudzinski, W. \& Plazinski, W. On the applicability of the pseudo-second order equation to represent the kinetics of adsorption at solid/solution interfaces: a theoretical analysis based on the statistical rate theory. Adsorption 15, 181-192 (2009).

27. Rauf, M. A., Bukallah, S. B., Hamour, F. A. \& Nasir, A. S. Adsorption of dyes from aqueous solutions onto sand and their kinetic behavior. Chem. Eng. J. 137, 238-243 (2008).

28. Doğan, M., Özdemir, Y. \& Alkan, M. Adsorption kinetics and mechanism of cationic methyl violet and methylene blue dyes onto sepiolite. Dyes Pigments 75, 701-713 (2007).

29. Arami, M., Limaee, N. Y. \& Mahmoodi, N. M. Evaluation of the adsorption kinetics and equilibrium for the potential removal of acid dyes using a biosorbent. Chem. Eng. J. 139, 2-10 (2008).

30. Lijklema, L. Interaction of Ortho-Phosphate with Iron(III) and Aluminum Hydroxides. Environ. Sci. Technol. 14, 537-541 (1980).

31. Makris, K. C., El-Shall, H., Harris, W. G., O'Connor, G. A. \& Obreza, T. A. Intraparticle phosphorus diffusion in a drinking water treatment residual at room temperature. J. Colloid Interf. Sci. 277, 417-423 (2004)

32. Hiemstra, T., Venema, P. \& Riemsdijk, W. H. V. Intrinsic Proton Affinity of Reactive Surface Groups of Metal (Hydr)oxides: The Bond Valence Principle. J. Colloid Interf. Sci. 184, 680-692 (1996).

33. Hiemstra, T. \& Van Riemsdijk, W. H. A surface structural model for ferrihydrite I: Sites related to primary charge, molar mass, and mass density. Geochim. Cosmochim. Ac. 73, 4423-4436 (2009).

34. Kandegedara, A. \& Rorabacher, D. B. Noncomplexing tertiary amines as "better" buffers covering the range of pH 3-11. Temperature dependence of their acid dissociation constants. Anal. Chem. 71, 3140-3144 (1999).

35. Gustafsson, J. P. Visual MINTEQ version 3.0. KTH, Stockholm, Sweden. http://vminteq.lwr.kth.se/.

36. Langmuir, I. The adsorption of gases on plane surfaces of glass, mica and platinum. J. Am. Chem. Soc. 40, 508 (1918).

37. Rouff, A. A. \& Juarez, K. M. Zinc Interaction with Struvite During and After Mineral Formation. Environmental Science \& Technology 48 (2014)

38. Kuzmič, P. Program DYNAFIT for the analysis of enzyme kinetic data: application to HIV proteinase. Anal. Biochem. 237, 260-273 (1996).

\section{Acknowledgements}

We gratefully acknowledge the support of National Natural Science Foundation of China (21307075).

\section{Author Contributions}

Y.M. performed experiments and wrote the manuscript. Q.Y. provided critically reviewed the manuscript.

\section{Additional Information}

Supplementary information accompanies this paper at http://www.nature.com/srep

Competing financial interests: The authors declare no competing financial interests.

How to cite this article: Mao, Y. and Yue, Q. Kinetic Modeling of Phosphate Adsorption by Preformed and In situ formed Hydrous Ferric Oxides at Circumneutral pH. Sci. Rep. 6, 35292; doi: 10.1038/srep35292 (2016). unless indicated otherwise in the credit line; if the material is not included under the Creative Commons license, users will need to obtain permission from the license holder to reproduce the material. To view a copy of this license, visit http://creativecommons.org/licenses/by/4.0/

(C) The Author(s) 2016 